University of Wollongong

Research Online

Australian Institute for Innovative Materials -

Papers

Australian Institute for Innovative Materials

$1-1-2017$

\title{
Quantification of gene-specific DNA methylation in oesophageal cancer via electrochemistry
}

\author{
Md Hakimul Haque \\ Griffith University \\ Vinod Gopalan \\ Griffith University \\ Md Nazmul Islam \\ Griffith University \\ Mostafa Kamal Masud \\ University of Wollongong, mkm590@uowmail.edu.au \\ Ripon Bhattacharjee \\ Griffith University
}

See next page for additional authors

Follow this and additional works at: https://ro.uow.edu.au/aiimpapers

Part of the Engineering Commons, and the Physical Sciences and Mathematics Commons

Research Online is the open access institutional repository for the University of Wollongong. For further information contact the UOW Library: research-pubs@uow.edu.au 


\title{
Quantification of gene-specific DNA methylation in oesophageal cancer via electrochemistry
}

\author{
Disciplines \\ Engineering | Physical Sciences and Mathematics \\ Publication Details \\ Haque, M. Hakimul., Gopalan, V., Islam, M. Nazmul., Masud, M. Kamal., Bhattacharjee, R., Hossain, M. Al., \\ Nguyen, N., Lam, A. K. \& Shiddiky, M. J. A. (2017). Quantification of gene-specific DNA methylation in \\ oesophageal cancer via electrochemistry. Analytica Chimica Acta, 976 84-93.
}

\section{Authors}

Md Hakimul Haque, Vinod Gopalan, Md Nazmul Islam, Mostafa Kamal Masud, Ripon Bhattacharjee, Md. Shahriar Al Hossain, Nam-Trung Nguyen, Alfred K. Lam, and Muhammad J. A Shiddiky 


\section{Quantification of Gene-specific DNA Methylation in Oesophageal Cancer via Electrochemistry}

Md. HakimulHaque ${ }^{\mathrm{a}, \mathrm{b}}$, Vinod Gopalan ${ }^{\mathrm{a} *}$, Md. Nazmul Islam ${ }^{\mathrm{b}}$, Mostafa Kamal Masud ${ }^{\mathrm{b}, \mathrm{c}}$,Ripon Bhattacharjee $^{\mathrm{b}}$, Md Shahriar Al Hossain ${ }^{\mathrm{c}}$, Nam-TungNguyen ${ }^{\mathrm{b}}$, Alfred K. Lam ${ }^{\mathrm{a}^{*}}$, and Muhammad J. A. Shiddiky ${ }^{\text {b* }}$

${ }^{\mathrm{a} C a n c e r}$ Molecular Pathology laboratory in Menzies Health Institute Queensland, Griffith University and School of Medicine, Gold Coast, Australia

${ }^{\mathrm{b}}$ School of Natural Sciences and Queensland Micro- and Nanotechnology Centre (QMNC) ${ }^{\mathrm{c}}$, Griffith University, Nathan Campus, Nathan, QLD 4111, Australia

${ }^{\mathrm{c} I n s t i t u t e}$ for Superconducting and Electronic Materials, Australian Institute for Innovative Materials, University of Wollongong, NSW 2519, Australia

*Corresponding author emails: $\quad$ v.gopalan@griffith.edu.au $(V G) ; \quad \underline{\text { a.lam@griffith.edu.au }}$ (AKL) and m.shiddiky@ griffith.edu.au (MJAS). 


\section{ABSTRACT}

Development of simple and inexpensive method for the analysis of gene-specific DNA methylation is important for the diagnosis and prognosis of patients in cancer. Herein, we report a relatively simple and inexpensive electrochemical method for the sensitive and selective detection of gene-specific DNA methylation in oesophageal cancer. The underlying principle of the method relies on the affinity interaction between DNA bases and unmodified gold electrode. Since the affinity trend of DNA bases towards the gold surface follows as adenine; (A) > cytosine $(\mathrm{C})>$ guanine $(\mathrm{G})>$ thymine $(\mathrm{T})$, a relatively larger amount of bisulfite-treatedadenine-enriched unmethylated DNA adsorbs on the screen-printed gold electrodes (SPE-Au) in comparison to the guanine-enriched methylated sample. The methylation levels were (i.e., different level of surface attached DNA molecules due to the base dependent differential adsorption pattern) quantified by measuring saturated amount of charge-compensating $\left[\mathrm{Ru}\left(\mathrm{NH}_{3}\right)_{6}\right]^{3+}$ molecules in the surface-attached DNAs by chronocoulometry as redox charge of the $\left.\left[\mathrm{Ru}_{(\mathrm{NH}}\right)_{6}\right]^{3+}$ molecules quantitatively reflects the amount of the adsorbed DNA confined at the electrode surface. The assay could successfully distinguish methylated and unmethylated DNA sequences at single $\mathrm{CpG}$ resolution and as low as $10 \%$ differences in DNA methylation. In addition, the assay showed fairly good reproducibility $(\% \mathrm{RSD}=\langle 5 \%)$ with better sensitivity and specificity by analysing various levels of methylation in two cell lines and eight fresh tissues samples from patients with oesophageal squamous cell carcinoma. Finally, the method was validated with methylation specific-high resolution melting curve analysis and Sanger sequencing methodsto study the methylation in oesophageal cancer samples.

Keywords: DNA methylation, gene-specific methylation, Electrochemical detection, Chronocoulometry, Oesophageal squamous cell carcinoma 


\section{Introduction}

DNA methylation is one of the clinically relevant epigenetic biomarkers that regulate gene expression via controlling transcriptional alteration, genomic stability, $\mathrm{X}$ chromosome inactivation, genomic imprinting and mammalian cell development[1]. Recent studies on epigenetic research demonstrate that aberrant DNA methylationplays a critical role in the pathophysiology of human cancers including oesophageal squamous cell carcinoma (ESCC)[2,3]. For example, gene-specific promoter hypermethylation is an important driver in the development and progression of many human cancers viatranscriptional inactivation and suppressing of gene function[4-8].More recently, it has also been demonstrated that DNA methylation can be used as tumour-specific therapeutic targets in ESCC [2].Therefore,sensitive and specific profiling of gene specific DNA methylation in ESCC could have potential implication for prediction of prognosis as well as to therapy response in clinical settings.

Until recently, gene specific DNA methylation in ESCC is generally detected via methylation specific PCR approaches along with bisulfite sequencing $[9,10]$. Over the past several decades, a variety of molecular biological approaches includingmethylation-sensitive single nucleotide-primer extension, methylight, methylation-sensitive high resolution melting, enzyme-linked immunosorbent assay (ELISA) based methylation assays, mass spectroscopy and fluorescence readout based methodshave been conspicuously exploited to quantify the level of the DNA methylation in many human cancers [11-15]. However, most of these approaches are relatively simpler and robust but typically require large sample volumes, sophisticated instruments, multi-step procedures, hazardous radiolabeling, complex fabrication, expensive antibodies, etc. Furthermore, these assays are affected by multiple 
external controls for quantitative analysis, background fluorescence interference, high labour and bioinformatics costswhich limit their use in routine clinical applications.

In recent years, much attention has been focused on thedevelopment ofsensitive, specific, relatively simple and inexpensive method for the analysis ofDNA methylation using electrochemistry, colorimetry, surface plasmon resonance and Raman scattering readouts [1722].While most of these readout methods have theirown merits and demerits, electrochemical readout offersadditional advantages in clinical diagnosticsapplications due to their relatively higher sensitivity and specificity, cost-effectiveness and compatibility with the miniaturization[23-25].In these assays, sensor requires a surface-attached capture probe to hybridize the complementary target sequence, and form duplex DNA that intercalatively bind with a redox-active transition-metal cations (e.g., $\left[\mathrm{Ru}\left(\mathrm{NH}_{3}\right)_{6}\right]^{3+}$ ) for the generation of electrochemical signals [26-29]. As described in many conventional electrochemical assays [30-33], the saturated amount of charge-compensation $\left[\mathrm{Ru}\left(\mathrm{NH}_{3}\right)_{6}\right]^{3+}$ complex $(\mathrm{RuHex})$ on the electrode surface is electrochemically determined, which is directly proportional to the number of negatively charged phosphate residues and thereby the surface density of the target DNA.

Previously, we demonstrated the use of direct adsorption of bisulfite treated and asymmetric PCR-amplified DNA sequences on to an unmodified gold electrode (without the use of complementary capture probe and hybridization step) to quantify the level of DNA methylation present in the sequence via measuring the total adsorbed DNA on to the electrode surface $[34,35]$. Since the adsorption (i.e., physisorption) trend of the DNA bases to gold surfaces follows as adenine $(\mathrm{A})>\operatorname{cytosine}(\mathrm{C})>$ guanine $(\mathrm{G})>$ thymine $(\mathrm{T})[36,37]$, two DNA sequences with different methylation patterns (i.e., bisulfite treated adenine-enriched unmethylated and guanine-enriched methylated DNA sequences) should have different adsorption affinity towards gold surface. Indeed, a relatively large amount of unmethylated 
DNA was adsorbed on the gold electrode in comparison to the methylated DNA. In this system, we showed that monitoring the Faradaic current generated by the $\left[\mathrm{Fe}(\mathrm{CN})_{6}\right]^{3-14-}$ system alone could be used for the interrogation of DNA methylation levelpresent in the bisulfite treated samples[34,35]. While this assay is relatively simple, it follows an electron transfer kinetic-based mechanism, where density of the DNA sequences at the electrode surface should be sufficiently low[31]. Additionally, the risk of false-positive responses at low concentration of target is well known when using a detection technique based onattenuation of the interfacial electron transfer reaction of a redox process (i.e., "signal-off" approach).

In order to avoid this complexity, in the current study, weexplored whether simply monitoring the total charge generated by the electrostatically-attached RuHex onto the adsorbed DNA could report on the level of DNA methylation present in samples, where generated total redox charge is the function of adsorbed DNA sequences on the electrode surface [26-29]. Since in this "signal-on" approach,the charge of the RuHex complex is quantitatively reflecting the amount of the adsorbed DNA at the electrode surface[30], the electrochemical signal generated by the chronocoulometric (CC) interrogation of DNAbound RuHex will give the level of methylation present in the amplified samples.It is also important to note that unlike RuHexbased conventional methods [30], the current method detects DNA methylation by simply monitoring the adsorbed target DNA on an unmodified SPE-Au electrode. Since we use direct adsorption of target DNA on an unmodified electrode rather than the conventional biosensing approach of using recognition and transduction layers, this method substantially simplifies the detection system by avoiding the complicated chemistries underlying each step of the sensor fabrication.

In this method,we first optimized the adsorption parameters (i.e., adsorption time, $\mathrm{pH}$ of the solution, and concentration of DNA) forthe direct adsorption of target DNA onto the 
unmodified SPE-Au surface. Then, we detectedthe level of promoter methylation present in FAM134B gene in a panel of oesophageal squamous cell carcinoma (ESCC) cell lines and tissue samples derived from patients withESSC. We also validated the results with methylation specific-high resolution melting (MS-HRM) curve analysis and Sanger sequencing.

\section{Experimental}

\subsection{Genomic DNA preparation}

All reagents and chemicals were analytical grade and purchased from Sigma Aldrich (St Louis, MO, USA) unless otherwise noted. UltraPure DNase/RNase-free distilled water was obtained from Invitrogen (Carlsbad, CA, USA). Whole genome amplification DNA was prepared according to the manufacture's protocol from REPLI-g whole genome amplification kit (Qiagen, Hilden, Germany). Two ESCC cell lines (HKESC-1 and HKESC-4) were kindly provided from our research group [38-39].Another ESCC cell line, KYSE-510, purchased from Leibniz Institute DSMZ (German collection of microorganisms and cell cultures). 100\% methylated Jurkat genomic DNA was obtained from New England Biolabs (Ipswich, MA, USA). Eight fresh frozen tissue samples from patients with ESCC and two non-neoplastic oesophageal tissues (as controls) were recruited for this study. Ethical approval was taken from the Griffith University human research ethics committee for the use of these samples (GU Ref Nos: MED/19/08/HREC and MSC/17/10/HREC). After histopathological confirmation, genomic DNA was purified from all ESCC tissue samples with all prep DNA/RNA mini kit (Qiagen, Hilden, Germany), according to the manufacturer's protocols. Blood and cell culture DNA mini kit (Qiagen, Hilden, Germany) was used for the purification of DNA from ESCC cell lines. All patients had not received pre-operative were free from radio/chemotherapy, matched with gender (all male) and clinical staging (stage III \& IV). 
Mean age group of the patients were $65 \pm 14$ ranging from 45 to 74 years. Screen-printed gold electrodes were acquired from Dropsens (Spain).

\subsection{Bisulfite modification}

Bisulfite conversion and purification of the genomic DNA was performed with MethylEasyXceed kit (Human Genetic Signatures Pty. Ltd., NSW, Australia) as recommended by the manufacturer. DNA quantification and purity was checked via Nanodrop Spectrophotometer (BioLab, Ipswich, MA, USA). Concentration of bisulfite treated DNA was noted in $\mathrm{ng} / \mu \mathrm{L}$ and then stored at $-20^{\circ} \mathrm{C}$ until use. Approximately $500 \mathrm{ng}$ genomic DNA from each samples were the starting amount for the bisulfite treatment.

\subsection{DNA quantification}

The DNA copy number normalization of FAM134B (JK1) genes in bisulfite treated cell and WGA DNA samples were analysed by the Rotor-Gene Q PCR detection system (Qiagen, Hilden, Germany). qRT-PCR was performed in a total volume of $10 \mu \mathrm{L}$ reaction mixture containing $5 \mu \mathrm{L}$ of $2 X$ SensiMix SYBR No-ROX master mix (Bioline, London, UK), $1 \mu \mathrm{L}$ of each $250 \mathrm{nM}$ primer, and $1 \mu \mathrm{L}$ of equal concentrated target cell and WGA DNA samples with $2 \mu \mathrm{L}$ of nuclease-free water. Thermal cycling programs encompassed initial denaturation and activate the hot start DNA polymerase in one cycle of 7 minutes at $95{ }^{\circ} \mathrm{C}$ followed by 40 cycles of 10 seconds at $95^{\circ} \mathrm{C}$ (denaturation), 30 seconds at $60^{\circ} \mathrm{C}$ (annealing) and 20 seconds at $72^{\circ} \mathrm{C}$ (extension).

\subsection{Asymmetric PCR}

Asymmetric PCR of the bisulfite treated DNA was carried out using AmpliTaq Gold 360 master mix (ThermFisher scientific, Waltham, MA USA) to generate ss-DNA amplicons. 
Asymmetric PCR was performed by suing $60 \mu \mathrm{L}$ reaction mixtures comprising $30 \mu \mathrm{L}$ of AmpliTaq Gold 360 master mix, $1 \mu \mathrm{L}$ of $125 \mathrm{nM}$ forward primer and $375 \mathrm{~nm}$ reverse primer, $1 \mu \mathrm{L}$ of $30 \mathrm{ng}$ bisulfite treated DNA and $28 \mu \mathrm{L}$ of nuclease-free water. PCR cycling programs was performed under the following conditions: $95^{\circ} \mathrm{C}$ for 10 minutes followed by 49 cycles of 30 seconds at $95^{\circ} \mathrm{C}$ (denaturation), 30 seconds at $61^{\circ} \mathrm{C}$ (annealing) and 20 seconds at $72^{\circ} \mathrm{C}$ (extension).

\subsection{Determination of the surface area of the electrodes}

Screen-printed electrode with the three-electrode system printed on a ceramic substrate (length $33 \times$ width $10 \times$ height $0.5 \mathrm{~mm}$ ) were purchased from Dropsens (Spain). In the threeelectrode system, working ( $\mathrm{SPE}-\mathrm{Au}$, diameter $=4 \mathrm{~mm})$, counter and reference electrodes were gold, platinum, and silver-modified electrodes. The effective working area of the electrodes were determined under cyclic voltammetric conditions for the one-electron reduction of $\mathrm{K}_{3}\left[\mathrm{Fe}(\mathrm{CN})_{6}\right][2.0 \mathrm{mM}$ in water $(0.5 \mathrm{M} \mathrm{KCl})]$ and use of the Randles-Sevcikeqn $(1)$

$$
i_{\mathrm{p}}=\left(269 \times 10^{5}\right) n^{3 / 2} A D^{1 / 2} C v^{1 / 2}
$$

where $i_{\mathrm{p}}$ is the peak current $(\mathrm{A}), n$ is the number of electrons transferred $\left(\mathrm{Fe}^{3+} \rightarrow \mathrm{Fe}^{2+}, n=\right.$ 1), $A$ is the effective area of the electrode $\left(\mathrm{cm}^{2}\right), D$ is the diffusion coefficient of $[\mathrm{Fe}(\mathrm{CN}) 6]^{3-}$ (taken to be $\left.7.60 \times 10^{-5} \mathrm{~cm}^{2} \mathrm{~s}^{-1}\right), C$ is the concentration $(\mathrm{mol} \mathrm{cm}-3), v$ is the scan rate $\left(\mathrm{Vs}^{-1}\right)$.

\subsection{Electrochemical measurements of DNA methylation}

All electrochemical measurements were performed on a $\mathrm{CH} 1040 \mathrm{C}$ potentiostat $(\mathrm{CH}$ Instruments, TX, USA). Cycleicvoltammetric (CV) experiments were performed in $10 \mathrm{mM}$ PBS solution containing $2 \mathrm{mM}\left[\mathrm{K}_{3} \mathrm{Fe}(\mathrm{CN})_{6}\right]$ electrolyte solution. Chronocoulometric readouts 
were obtained in $10 \mathrm{mM}$ tris buffer $(\mathrm{pH} 7.4)$ in the presence and absence of $50 \mu \mathrm{M}$ RuHex with a potential step of $5 \mathrm{mV}$ and pulse width of $250 \mathrm{~ms}$, and sample interval of $2 \mathrm{~ms}$. For synthetic DNA samples, $5 \mu \mathrm{L}$ (diluted in SSC5X buffer to get $100 \mathrm{nM}$ of DNA) sample was adsorbed on SPE-Au surface. For clinical samples analysis, $5 \mu \mathrm{L}$ (diluted in SSC5X buffer to get $50 \mathrm{ng}$ of DNA) were used for adsorption experiments. The electrodes were then washed three times with PBS prior to perform CC readouts. The total redox charge $\left(Q_{\text {total }}\right)$ corresponding to RuHex electrostatically bound to the surface localized DNA was calculated usingEq. 2.

$$
Q_{\text {total }}=Q_{\text {target }}-Q_{d l} \ldots \ldots \ldots \ldots \ldots \ldots \ldots
$$

where $Q_{\text {target }}$ is the charge flowing through the target DNA-attached (methylated or unmethylated) electrode containing both Faradaic (redox) and non-Faradaic (capacitive) charges, and $Q_{\mathrm{dl}}$ is the double-layer charge (capacitive charge) from the intercept at $t=0$, respectively. The redox charge difference $(\Delta \mathrm{Q})$ in $\mathrm{CC}$ signals between unmethylated and methylated was estimated using Eq. 3.

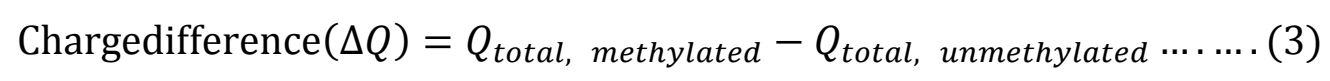

where $Q_{\text {total, methylated }}$ and $Q_{\text {total, unmethylated }}$ are the $\mathrm{CC}$ signalsestimated for the unmethylated and methylated samples, respectively.

\subsection{Methylation specific-high resolution melting (MS-HRM) curve analysis}

MS-HRM was carried out based on the modified versions of the previously published procedure [13]. Briefly, HRM curve analysis was demonstrated on the Rotor-Gene Q detection system (Qiagen) using the Rotor-Gene ScreenClust Software. PCR was performed in a $10 \mu \mathrm{L}$ total volume containing $5 \mu \mathrm{L}$ of $2 \mathrm{X}$ sensimix HRM master mix, $1 \mu \mathrm{L}$ of $20 \mathrm{ng} / \mu \mathrm{L}$ 
bisulfite modified genomic DNA, $2 \mu \mathrm{L}$ RNase free water and $1 \mu \mathrm{L}$ of each primer. The thermal profile comprised $15 \mathrm{~min}$ at $95^{\circ} \mathrm{C}$, followed by 50 cycles of 30 seconds at $95^{\circ} \mathrm{C}, 30$ seconds at $61^{\circ} \mathrm{C}$ and 20 second at $72^{\circ} \mathrm{C}$. HRM analyses were carried out at temperature ramping from $70-95^{\circ} \mathrm{C}$. The normalization of melting curve was performed as previously reported[40].

\subsection{Sanger sequencing}

To further confirm the methylation status of FAM134B promoter region, we employed Sanger sequencing analysis. The purified DNA was mixed with the primer (12 ng of DNA + $1 \mu \mathrm{L}$ of 10 pmol primer in $12 \mu \mathrm{L}$ of $\mathrm{H}_{2} \mathrm{O}$ ) sequence using the Big Dye Terminator (BDT) chemistry Version 3.1 (Applied Biosystems). Sanger sequencing was performed and analyzed using a 3730xl Capillary sequencer (Applied Biosystems) under standardised cycling PCR conditions in the Australian Genome Research Facility (AGRF, Brisbane).

\subsection{Statistical analysis}

Statistical analyses were performed via pairwise comparisons between two conditions using student's t-test. Significance level of the tests was taken at $\mathrm{p}<0.05$.

\section{Results and discussion}

\subsection{Principle of the quantification of gene specific DNA methylation assay}

We first extracted double stranded (ds)-DNA from the cancer cell lines and clinical tissue samples from ESCC patients to demonstrate the working principle of the method. We performed a bisulfite conversion step for converting unmethylated cytosines in ds-DNA into uracils while methylated cytosines remain unchanged. Then, an asymmetric PCR amplification step was performed to convert all ds-DNA into ss-DNA amplicon. In this step, 
cytosines in the complementary strand would be copied into guanines and uracilsinto adenines ensuing guanine-enriched methylated and adenine-enriched unmethylated samples.The samples were then directly adsorbed on a SPE-Au electrode surface.The adsorbed ss-DNA samples were detected by CC interrogation in presence of an electroactive complexRuHex. Here, RuHex cations act as the signaling molecule that binds to the anionic phosphate of DNA strands in a stoichiometric manner[41]. Previous studies have clearly showed that redox charge of RuHex is quantitatively indicating the amount of DNA strands localized at the electrode surface[13,41-42].In the present method, since the adsorption strength of DNA bases towards gold differ as $A>C>G>T$, adenine-enriched unmethylated DNA leadsto a higher level of adsorbed DNA on the gold electrode surface in comparison to guanine-enriched methylated DNA, resulting in a significant difference in CC signals for unmethylated and methylated targets. As schematically presented in Fig.1, methylated DNA results in a relatively low level of $\mathrm{CC}$ charges (i.e., a significant charge density $\left./ \mu \mathrm{Ccm}^{-2}\right)$ in comparison to that of the unmethylated DNA.

\subsection{Synthetic sample design}

Recent studies suggested thatalterations in $F A M 134 B$ gene havea significantimpact in gastrointestinal carcinomas and neurological diseases via regulating its expression patterns and cellular autophagy [43-46]. It has also been reported that FAM134B is mutated in metastatic lymph node tissues and its DNA copy number significant alteratedin oesophageal squamous cell carcinoma tissues [43].In this proof-of-concept study, we have used gold-DNA affinity interaction for detecting gene-specific DNA methylation in FAM134Bpromoter region containing designated $\mathrm{CpG}$ sites located within a length of 48 bases. In order to execute our approach, we have designed synthetic samples containing $0,1,5$ and $11 \mathrm{CpGsites}$ 
within the promoter region of $F A M 134 B$ gene which mimic the bisulfite treated and asymmetric PCR processed methylated and unmethylated DNA regions.

\subsection{Assay Optimization}

The extent of the adsorption of the target DNA on unmodified SPE-Au depends on the adsorption condition such as adsorption time, solution $\mathrm{pH}$ and amount of DNA. We first optimized the adsorption time (5-40 mins) of target DNA samples by measuring the redox charge differences between the $10 \mathrm{ng} / \mu \mathrm{L}$ synthetic methylated $(11 \mathrm{CpG})$ and unmethylated $(0$ CpG) DNA in a solution of $\mathrm{pH} 7$. As depicted in Fig. 2A, the maximum level of difference in charge densities between methylated and unmethylated samples was achieved at 5 min of adsorption time and gradually decreases with increasing time. At $>20$ min of the adsorption time, the difference in charge densities is minimum. This can be explained by the fact that longer adsorption time led to the saturation of the electrode surface with the methylated and unmethylated samples, causing a similar level ofthe surface confined redox process (i.e., RuHex localized at electrode) in CCfor both the methylated and unmethylated casesproviding two CC signals with almost identical magnitudes. Therefore, 5 min of the adsorption time was chosen for all subsequent experiments.

We further investigated the effect of DNA concentration $(2.5-40 \mathrm{ng} / \mu \mathrm{L})$ on the change of the charge densitiesbetween the methylated and unmethylated DNA samplesonto a SPE-Auin a solution of $\mathrm{pH} 7$ for 5 min of adsorption.As seen in Fig. 2B, a significant change in charge densities (80.24)between methylated and unmethylated samples was found at the DNA concentration of $5 \mathrm{ng} / \mu \mathrm{L}$. The maximum redox charge density difference i.e., 95.54was achieved using $10 \mathrm{ng} / \mu \mathrm{L}$ of DNA between these two samples. This is related to the increasing level of adsorbed DNA (i.e., larger RuHex redox probes) on the electrode surface with increasing concentrations.At $>20 \mathrm{ng} / \mu \mathrm{L}$ DNA concentration, a sharp decrease in thecharge 
densities changes was observed. For example, $40 \mathrm{ng} / \mu \mathrm{L}$ of DNA concentration resulted the charge densities changes of 40.34between methylated and unmethylated samples. These findings clearly indicate that the amount of DNA at $>10 \mathrm{ng} / \mu \mathrm{L}$ offers almost similar level of CC signals for both the methylated and unmethylated sequences. This can be explained by the fact that saturation of both sequences on the electrode surface was achieved within 5 min of adsorption at higher DNA concentrations which eventually leads to a similar level of redox charge densities. Thus, $10 \mathrm{ng} / \mu \mathrm{L}$ of DNA concentration wasselected as an optimal concentration for all subsequent experiments. We then estimated the effect of the $\mathrm{pH}$ of the solution on the adsorption of target DNA by varying the $\mathrm{pH}$ of the solution from 3.0 to 9.5 . Fig. 2C clearly showed thatthe redox charge density changes between methylated and unmethylated DNA samples werefound to be 35.25at $\mathrm{pH}$ 3.0. The optimalcharge density changes 95.55was achieved at neutral $\mathrm{pH}($ i.e., 7), whereas at $>\mathrm{pH}=7.0$, a gradual decreases in charge density changes was recorded. These results clearly showed that $\mathrm{pH}$ of the buffer solution influence the competition between DNA and gold electrostatic forces (i.e., inherent interaction between DNA bases and gold electrodes). At neutral $\mathrm{pH}$, negative charge of the phosphate backbone of DNA is optimal to hinder the adsorption of methylated samples while still allowing the unmethylated DNA with higher adenine contents to be adsorbed strongly. At basic $\mathrm{pH}$, the gold surface would be more negatively charged and electrostatic repulsion with the negatively-charged phosphate backbone of DNA could reduce overall DNA adsorption.On the other hand, at the lower $\mathrm{pH}$ (3), cytosines and adenine in the target sequences would be protonated which could facilitate faster adsorption for methylated and unmethylated samples resulting saturation ofboth targets on the gold surface within a very short time leading to a reduced level of charge density changes. Therefore, we selected $\mathrm{pH} 7$ as an optimal $\mathrm{pH}$ for our assay. 


\subsection{Synthetic sample analysis}

To evaluate the applicability of our approach for the detection ofvarious level of $\mathrm{CpG}$ methylation within the promoter region of FAM134Bgene, four synthetic DNA samples containing 0,1,5 and $11 \mathrm{CpG}$ sites were examined. Fig. 3 shows that the decrease of the redox chargedensities is a function of the number of $\mathrm{CpG}$ cites. This is due to the decrease of the adenine contents with increasing methylated $\mathrm{CpG}$ sites in the target sequence (i.e., low level of adsorbed DNA leading to the lowering of the charge densities). The linear regression

equation wasestimated to be $\mathrm{y}\left(\right.$ charge,$\left.\mu \mathrm{Ccm}^{-2}\right)=-8.2926$ (number ofCpG sites) +103.9 with a correlation coefficient $\left(R^{2}\right)$ of 0.9999 . The level of redox charge responses showed in Fig.2 clearlyindicates that our assay can effectively detect DNA methylation at a single CpG level of resolution. A similar result has also been reported previously based on gold-DNA [34]and graphene-DNA [40] affinity interaction based approaches.

\subsection{Heterogonous sample analysis}

Heterogeneous methylation can arise as a mixture of fully methylated and unmethylated DNA in varying proportions in tissue samples from cancer patients[47].A heterogeneous mixture of cancer cells may contain both fully unmethylated and methylated DNA like imprinted gene H19[48].Accuratequantification of heterogeneous DNA methylation pattern plays critical role for the detection and prediction of clinical prognosis in human cancers[47]. It is therefore important to screen the degree of methylation pattern in a high background of unmethylated DNA samples. To evaluate the assay performance for detecting heterogeneous DNA methylation pattern, we analysed the dependence of the CCresponses on various degree of methylation. The samples were made by mixing synthetic standards of methylated and unmethylated DNA sequences to get $0 \%, 10 \%, 25 \%, 50 \%, 75 \%, 90 \%$ and $100 \%$ methylation, Fig.4. The total change densitiesdecrease with increasing levels of methylation, probably due 
to the increasing adenine contents in the target DNA sequences. The linear regression equation was found to be $\mathrm{y}$ (charge, $\left.\mu \mathrm{Ccm}^{-2}\right)=-0.8653$ (\% methylation)+102.6with a correlation coefficient $\left(R^{2}\right)$ of 0.9998 . A methylation change as low as $10 \%$ could be detected from $10 \mathrm{ng} / \mu \mathrm{L}$ of DNA. This data clearly demonstrate that our approach is sensitive enough in detecting methylated DNA in the nanogram regime. It is important to note that this level of data was much better than the findings of our previous gold-DNA based approach $[34,35]$, and was also comparable to recent approaches [18-22].

\subsection{Gene specific methylation detection and validation in cell line and clinical sample}

To demonstrate a complex biological application, we applied our assay to detect the methylationstatus at the eleven $\mathrm{CpG}$ sites of the targeted FAM134B promoter which have been reported to be methylated in ESCC [40]. Purified DNA amplicons obtained from whole genome amplification and Jurkat DNA was used as fully unmethylated DNA and 100\% methylated control, respectively. For avoiding any PCR bias, we quantified the gene copy number prior to PCR amplification [34,35].Purified genomic DNA samples generated from three ESSC cell lines were then amplified asymmetrically and analyzed using our approach under the optimized conditions, Fig. 5A. As indicated in Fig. 5B and C, significant redox charge responses were observed in three cancer cell lines, unmethylated WGA, and 100\% methylated Jurkat DNA samplessignifying the presence of different percentage of methylation. When compared to that of the fully unmethylated WGA and $100 \%$ methylated Jurkat DNA samples, the level of the total redox charges obtained forthe DNA sequences derived from HKESC-4, KYSE-510 and HKESC-1 cell lines indicated that HKESC-4 is partially and other two could be highly methylated (i.e., hypermethylated) at FAM134B promoter gene. The relative standard deviation (\%RSD) over three independent experiments in quantifying DNA methylation from these cell line samples analysis was found to be $<5 \%$. 
These data were validated with MS-HRM curve analysis and Sanger sequencing. As can be seen in Fig S1, MS-HRM curve analysis showed that DNA samples derived from HKESC-4 is partially methylated while KYSE-510 and HKESC-1 DNA samples are hypermethylated. Moreover, Sanger sequencing also confirmed the different degree methylation in WGA, Jurkat DNA and different ESCC cell lines sample (Fig. S2 and 3). These data clearly indicate that the proposed assay could be a useful alternative for detecting $F A M 134 B$ promoter gene methylation in cell-derived samples.

To further demonstrate the potential utility of our method in analysing clinical samples, we extended our assay to analyse eight tissue DNA samples derived from patients with primary ESCC. Two oesophageal non-cancerous tissue DNA samples were also used as a control (see Experimental for details). As indicated in Fig. 5D, all samples showed different degree of methylation. The level of total redox chargeof two normal samples clearly showed that these two samples are unmethylated in comparison to that of the WGA and Jurkat DNA samples. Similarly, by comparing the level of totalredox charges found for WGA and Jurkat DNA samples (Fig. 5C), we can estimate that four DNA samples derived from P5, P6, P7 and P8 cancer patients were relatively highly methylated, while P1, P2, P3 and P4 samples were partially methylated (i.e., low methylation) at $F A M 134 B$ promoter gene. We then validated our assay performance with well-known MS-HRM curve analysis and Sanger sequencing. As can be seen in Fig S1B and C, MS-HRM curve analysis identified almost similar methylation level in WGA, N1 and N2 samples. Also, P5, P6, P7 and P8 cancer patients were highly methylated with respect to that of P1, P2, P3 and P4 samples. Sanger sequencing also confirmed that P5, P6, P7 and P8 samples were relatively highly methylated (see typical sequencing data in Fig.S2-S4). Moreover, \%RSD over three independent experiments in quantifying DNA methylation from clinical samples analysis were found to be $<5 \%$. These dataclearly indicated that $\mathrm{CC}$ signals generated by our assay were able to quantify different 
degree of DNA methylation in ESCC tissue samples. Also, our assay is highly reproducibile with greater sensitivity and specificity without costly fluorescence labels used in many of current methylation detection techniques[49-51]. In addition, validation studies with MSHRM curve analysis and Sanger sequencing further suggested that our assay could detect DNA methylation in easy and inexpensive way from cancer patients.

Our method offers several advantages over current methodologies. First, the method involves the direct adsorption of target DNA onto an unmodified electrode rather than the conventional biosensing approach of using recognition and transduction layers, and hence it substantially simplifies the detection method by avoiding the use of complicated chemistries underlying each step of the sensor fabrication. It also avoids the use of capture probe as well as hybridization step. Second, it circumvents the need for the use of radioactive labels, methylation-sensitive restriction enzymes, antibodies, and sequencing analysis. Third, the use of commercially available and disposable SPE-Au (containing a three-electrode system) successfully eliminates the utilization of typical electrochemical cells, counter and reference electrodes thereby offering a relatively inexpensive ( USD \$5 per SPE-Au) platform for DNA methylation detection. Moreover, the use of SPE-Au potentially avoids the usual timeconsuming cleaning steps associated with conventional electrodes making the analysis much faster. Fourth, the detection step of our proposed assay can take only ten min in total (excluding bisulfite treatment and asymmetric PCR steps) to achieve electrochemical readout, which is considerably faster than many recent electrochemical DNA methylation assays $[13,29,40]$.

\section{Conclusion}

We have reported a simple and new method for the quantification of targeted FAM134B gene-associated DNA methylation via the different adsorption affinity interaction of DNA 
bases with gold. The detection was achieved by simply monitoring their direct adsorption of bisulfite-treated and PCR amplified sequences onto a SPE-Au. The adsorption of the DNA sequence representing methylated and unmethylated was then quantified via $\mathrm{CC}$ interrogation of the DNA-bound RuHex complexes. Most importantly, our developed assay can successfully quantify $F A M 134 B$ promoter methylation at varying level in a panel of ESCC cell lines and clinical samples from ESCC patients. The analytical performance of our method has been shown a good agreement with the data obtained using MS-HRM analysis and Sanger sequencing. We anticipated that our approach could be potentially useful for the detection of epigenetic biomarker in both clinical diagnostics and research.

\section{Acknowledgements}

This work was supported by the NHMRC CDF (APP1088966 to M.J.A.S.) and higher degree research scholarships (GUIPRS and GUPRS scholarships to M.H.H., M.N.I. and R.B) from the Griffith University.

\section{Appendix A. Supplementarydata}

Supplementary data associated with this article can be found in the online version at http://dx.doi.org/........... 


\section{References}

[1] K.D. Robertson, P.A. Jones, methylation: past, present and future directions, carcinogenesis, 21 (2000) 461-467.

[2] K. Ma, B. Cao, M. Guo, The detective, prognostic, and predictive value of DNA methylation in human esophageal squamous cell carcinoma, Clin. Epigenetics.8 (2016) 43.

[3] I.Y. Kuo, J.M. Chang, S.S. Jiang, C.H. Chen, I.S. Chang, B.S. Sheu, P.J. Lu, W.L. Chang, W.W. Lai, Y.C. Wang, Prognostic CpG methylation biomarkers identified by methylation array in esophageal squamous cell carcinoma patients, Int. J. Med. Sci. 11 (2014) 779-787.

[4] H.W. Chang, V. Chow, K.Y. Lam, W.I. Wei, A. Yuen, Loss of E-cadherin expression resulting from promoter hypermethylation in oral tongue carcinoma and its prognostic significance, Cancer 94 (2002) 386-392.

[5] Y. Delpu, P. Cordelier, W.C. Cho, J. Torrisani, DNA methylation and cancer diagnosis, 2013. Int. J. Mol. Sci. 14 (2013) 15029-15058.

[6] T.S. Wong, M.W. Man, A.K. Lam, W.I. Wei, Y.L. Kwong, A.P. Yuen, The study of p16 and 15 gene methylation in head and neck squamous cell carcinoma and their quantitative evaluation in plasma by real-time PCR, Eur. J. Cancer. 39 (2003) 1881-1887.

[7] M.L. Wong, Q. Tao, L. Fu, K.Y. Wong, G.H. Qiu, F.B. Law, P.C. Tin, W.L. Cheung, P.Y. Lee, J.C. Tang, G.S. Tsao, K.Y. Lam, S. Law, J. Wong, G. Srivastava, Aberrant promoter hypermethylation and silencing of the critical 3p21 tumour suppressor gene, RASSF1A, in Chinese oesophageal squamous cell carcinoma. Int. J. Oncol. 28 (2006) 767-773.

[8] A.W. Chai, A.K. Cheung, W. Dai, J.M. Ko, J.C. Ip, K.W. Chan, D.L. Kwong, W.T. Ng, A.W. Lee, R.K. Ngan, C.C. Yau, S.Y. Tung, V.H. Lee, A.K. Lam, S. Pillai, S. Law, M.L. Lung, Metastasis-suppressing NID2, an epigeneticallysilenced gene, in the pathogenesis of nasopharyngeal carcinoma and esophageal squamous cell carcinoma,Oncotarget. 7 (2016) 78859-78871.

[9] T. Kuroki, F. Trapasso, S. Yendamuri, A. Matsuyama, H. Alder, M. Mori, C.M. Croce, Promoter hypermethylation of RASSF1A in esophageal squamous cell carcinoma, Clin. Cancer Res. 9 (2003) 1441-1445.

[10] C. Long, B. Yin, Q. Lu, X. Zhou, J. Hu, Y. Yang, F. Yu, Y. Yuan, Promoter hypermethylation of the RUNX3 gene in esophageal squamous cell carcinoma, Cancer Invest. 25 (2007) 685-690.

[11] M.L. Gonzalgo, P.A. Jones, Rapid quantitation of methylation differences at specific sites using methylation-sensitive single nucleotide primer extension (MsSNuPE), Nucleic Acids Res. 25 (1997) 2529-2531.

[12] C.A. Eads, K.D. Danenberg, K. Kawakami, L.B. Saltz, C. Blake, D. Shibata, P.V. Danenberg, P.W. Laird, MethyLight: a high-throughput assay to measure DNA methylation, Nucleic Acids Res. 28 (2000) E32.

[13] T.K. Wojdacz, A. Dobrovic, Methylation-sensitive high resolution melting (MSHRM): a new approach for sensitive and high-throughput assessment of methylation, Nucleic Acids Res. 35 (2007) e41.

[14] M.N. Islam, S. Yadav, M.H. Haque, M. Ahmed, F. Islam, M.S.Al. Hossain, V. Gopalan, A.K. Lam, N.T. Nguyen, M.J.A. Shiddiky, Optical biosensing strategies for DNA methylation analysis, Biosens. Bioelectron. 2016, doi: 10.1016/j.bios.2016.10.034. 
[15] S. Kurdyukov, M. Bullock, DNA Methylation Analysis: Choosing the Right Method, Biology 5 (2016) 3.

[16]D. Kato, K. Goto, S. Fujii, A. Takatsu, S. Hirono, O. Niwa, Electrochemical DNA methylation detection for enzymatically digested $\mathrm{CpG}$ oligonucleotides Anal. Chem. 83 (2011) 7595-7599.

[17] D. Kato, N. Sekioka, A. Ueda, R. Kurita, S. Hirono, K. Suzuki, O. Niwa, A nanocarbon film electrode as a platform for exploring DNA methylation, J. Am. Chem. Soc. 130 (2008) 3716-3717.

[18] L.G. Carrascosa, A.A. Sina, R. Palanisamy, B. Sepulveda, M. A. Otte, S. Rauf, M.J.A. Shiddiky, M. Trau, Molecular inversion probe-based SPR biosensing for specific, label-free and real-time detection of regional DNA methylation, Chem. Commun. 50 (2014) 3585-3588.

[19] K.M. Koo, E.J. Wee, S. Rauf, M.J.A. Shiddiky, M. Trau, Microdevices for detecting locus-specific DNA methylation at $\mathrm{CpG}$ resolution, Biosens. Bioelectron. 56 (2014) 278-285.

[20]E.J.H.Wee, T. HaNgo, M. Trau, A simple bridging flocculation assay for rapid, sensitive and stringent detection of gene specific DNA methylation, Sci Rep. 5 (2015) 15028.

[21] E.J.H. Wee, S. Rauf, M.J.A. Shiddiky, A. Dobrovic, M. Trau, DNA ligase-based strategy for quantifying heterogeneous DNA methylation without sequencing, Clin. Chem. 61(2015) 163-171.

[22] Y. Wang, E.J.H. Wee, M. Trau, Accurate and sensitive total genomic DNA methylation analysis from sub-nanogram input with embedded SERS nanotags, Chem. Commun. 52 (2016) 3560-3563.

[23] E.L. Wong, J.J. Gooding, The electrochemical monitoring of the perturbation of charge transfer through DNA by cisplatin, J. Am. Chem. Soc. 129 (2007) 89508951.

[24] M. Labib, E.H. Sargent, S.O. Kelley, Electrochemical Methods for the Analysis of Clinically Relevant Biomolecules, Chem. Rev. 116 (2016) 9001-9090.

[25] S.M. Choi, D.M. Kim, O.S. Jung, Y.B.Shim, A disposable chronocoulometric sensor for heavy metal ions using a diaminoterthiophene-modified electrode doped with graphene oxide, Anal. chim. Acta. 892 (2015) 77-84.

[26] G.L. Wang, L.Y. Zhou, H.Q. Luo, N.B. Li, Electrochemical strategy for sensing DNA methylation and DNA methyltransferase activity, Anal. Chim.Acta. 768 (2013) 76-81.

[27] J. Ji, Y. Liu, W. Wei, Y. Zhang, S. Liu, Quantitation of DNA methyltransferase activity via chronocoulometry in combination with rolling chain amplification, Biosens. Bioelectron. 85 (2016) 25-31.

[28] S. Sato, M. Tsueda, Y. Kanezaki, S. Takenaka, Detection of an aberrant methylation of $\mathrm{CDH} 4$ gene in PCR product by ferrocenylnaphthalenediimidebased electrochemical hybridization assay Anal. Chim.Acta. 715 (2012) 42-48.

[29] H. Zhang, Y. Yang, H. Dong, C. Cai, A superstructure-based electrochemical assay for signal-amplified detection of DNA methyltransferase activity, Biosens. Bioelectron. 86 (2016) 927-932.

[30] A.B.Steel, T.M.Herne, M.J.Tarlov, Electrochemical quantitation of DNA immobilized on gold, Anal. Chem. 70 (1998) 4670-4677.

[31] J. Zhang, S. Song, L. Wang, D. Pan, C. Fan, A gold nanoparticle-based chronocoulometric DNA sensor for amplified detection of DNA, Nat. Protoc. 2 (2007) 2888-2895. 
[32] E.L. Wong, J.J. Gooding, A selective electrochemical DNA biosensor, Anal. Chem. 78 (2006) 2138-2144.

[33] M.J.A. Shiddiky, A.A. Torriero, Z. Zeng, L. Spiccia, A.M. Bond, Highly selective and sensitive DNA assay based on electrocatalytic oxidation of ferrocene bearing zinc(II)-cyclen complexes with diethylamine, J. Am. Chem. Soc. 132 (2010) 10053-10063.

[34] A.A. Sina, S. Howell, L.G. Carrascosa, S. Rauf, M.J.A Shiddiky, M. Trau, eMethylsorb: electrochemical quantification of DNA methylation at $\mathrm{CpG}$ resolution using DNA-gold affinity interactions, Chem. Commun. 50 (2014) 13153-13156.

[35] K.M. Koo, A.A. Sina, L.G. Carrascosa, M.J.A. Shiddiky, M. Trau, eMethylsorb: rapid quantification of DNA methylation in cancer cells on screen-printed gold electrodes, Analyst 139 (2014) 6178-6184.

[36] H. Kimura-Suda, D.Y. Petrovykh, M.J. Tarlov, L.J. Whitman, Base-dependent competitive adsorption of single-stranded DNA on gold, J. Am. Chem. Soc. 125 (2003) 9014-9015.

[37] J.J. Storhoff, R. Elghanian, C.A. Mirkin, R.L. Letsinger, Sequence-dependent stability of DNA-modified gold nanoparticles Langmuir18 (2002) 6666-6670.

[38] Y. Hu, K.Y. Lam, T.S. Wan, W. Fang, E.S. Ma, L.C. Chan, G. Srivastava, Establishment and characterization of HKESC-1, a new cancer cell line from human esophageal squamous cell carcinoma, Cancer Genet. Cytogenet. 118 (2000) $112-120$.

[39] L.C. Cheung, J.C. Tang, P.Y. Lee, L. Hu, X.Y. Guan, W.K. Tang, G. Srivastava, J. Wong, J.M. Luk, S. Law, Establishment and characterization of a new xenograft-derived human esophageal squamous cell carcinoma cell line HKESC4 of Chinese origin, Cancer Genet Cytogenet. 178 (2007) 17-25.

[40] M.H. Haque, V. Gopalan, S. Yadav, M.N. Islam, E. Eftekhari, Q. Li, L.G. Carrascosa, N.T. Nguyen, A.K. Lam, M.J.A. Shiddiky, Detection of regional DNA methylation using DNA-graphene affinity interactions, BiosensBioelectron. 87 (2016) 615-621.

[41] J. Zhang, S. Song, L., Zhang, L. Wang, H. Wu, D. Pan, C. Fan, Sequence-specific detection of femtomolar DNA via a chronocoulometric DNA sensor (CDS): effects of nanoparticle-mediated amplification and nanoscale control of DNA assembly at electrodes, J. Am. Chem. Soc. 128 (2006) 8575-8580.

[42] P.S. Ho, C.A. Frederick, D. Saal, A.H. Wang, A.Rich, The interactions of ruthenium hexaammine with Z-DNA: crystal structure of a $\mathrm{Ru}(\mathrm{NH} 3) 6+3$ salt of d(CGCGCG) at 1.2 A resolution, J. Biomol. Struct.Dyn. 4 (1987) 521-534.

[43] M.H. Haque. V. Gopalan, K.W. Chan, M.J.A. Shiddiky, R.A. Smith, A.K. Lam, Identification of Novel FAM134B (JK1) Mutations in Oesophageal Squamous Cell Carcinoma, Sci Rep 6 (2016) 29173.

[44] W.K. Tang, C.H. Chui, S. Fatima, S.H. Kok, K.C. Pak, T.M. Ou, K.S. Hui, M.M. Wong, J. Wong, S. Law, S.W. Tsao, K.Y. Lam, P.S. Beh, G. Srivastava, A.S. Chan, K.P. Ho, J.C. Tang, Oncogenic properties of a novel gene JK-1 located in chromosome $5 \mathrm{p}$ and its overexpression in human esophageal squamous cell carcinoma, Int. J. Mol. Med. 19 (2007) 915-923.

[45] K. Kasem, V. Gopalan, A. Salajegheh, C.T. Lu, R.A. Smith, A.K.Y. Lam, The roles of JK-1(FAM134B) expressions in colorectal cancer, Exp. Cell Res. 326 (2014) 166-173. 
[46] F. Islam, V. Gopalan, R. Wahab, R.A. Smith, B. Qiao, A.K. Lam, Stage dependent expression and tumor suppressive function of FAM134B (JK1) in colon cancer, Mol. Carcinog. 56 (2016) 238-249.

[47] T. Mikeska, I.L. Candiloro, A.Dobrovic, The implications of heterogeneous DNA methylation for the accurate quantification of methylation, Epigenomics. 2 (2010) 561-573.

[48] A. Kerjean, J.M. Dupont, C. Vasseur, D. Le Tessier, L. Cuisset, A. Pàldi, P. Jouannet, M. Jeanpierre, Establishment of the paternal methylation imprint of the human H19 and MEST/PEG1 genes during spermatogenesis, Hum. Mol. Genet. 9 (2000) 2183-2187.

[49] V.J. Bailey, H. Easwaran, Y. Zhang, E.S. Griffiths, A. Belinsky, J.G. Herman, S.B. Baylin, H.E. Carraway, T.H. Wang, MS-qFRET: a quantum dot-based method for analysis of DNA methylation, Genome Res. 19(2009) 1455-1461.

[50] I. Van der Auwera, W. Yu, L. Suo, L. Van Neste, P. van Dam, E.A. Van Marck, P. Pauwels, P.B. Vermeulen, L.Y. Dirix, S.J. Van Laere, Array-based DNA methylation profiling for breast cancer subtype discrimination,PLoS One, 5 (2010) e12616.

[51] J. Zhang, B. Xing, J. Song, F. Zhang, C. Nie, L. Jiao, L. Liu, F. Lv, S. Wang, Associated analysis of DNA methylation for cancer detection using CCP-based FRET Technique, Anal. Chem. 86 (2014) 346-350. 


\section{Figure Legends}

Fig. 1.Principle of the quantification of gene specific DNA methylation assay. The adenineenriched unmethylated ss-DNA adsorbsrelatively larger amount on SPE-Au electrode in compare to that of the guanine-enriched methylated ss-DNA. A significant electrochemical signals were generated by the $\mathrm{CC}$ interrogation of DNA-bound $\left.\mathrm{Ru}\left(\mathrm{NH}_{3}\right)_{6}\right]^{3+}$ complexes.Inset, typical CC signalsshowing the adenine-enriched unmethylated DNA that produceshigher CC charge in comparison to guanine-enriched methylated DNA.

Fig. 2.The redox charge difference obtained for the adsorption of unmethylated $(0 \mathrm{CpG})$ and methylated (11 CpG) DNA sequences at (A) various time (B) concentration and (C) $\mathrm{pH}$ of the solution. Each data point (A-C) represents the average of three repeat trails, and error bars represent the standard deviation of measurements $(\% \mathrm{RSD}=<5 \%$ for $n=3)$.

Fig.3.(A)Typical $\mathrm{CC}$ curves for the sample containing $0,1,5,11 \mathrm{CpG}$ site and its corresponding background signal. (B)CCreadout represent redox charges of RuHex bound to DNA with respect to the designated $\mathrm{CpG}$ sites. Each data point represents the average of three repeat trails, and error bars represent the standard deviation of measurements $(\% \mathrm{RSD}=$ $<5 \%$ for $n=3)$.

Fig.4.(A) TypicalCC curves for the sample containing $0 \%, 10 \%, 25 \%, 50 \%, 75 \%, 90 \%$ and $100 \%$ and their corresponding background signals. (B) $\mathrm{CC}$ readout represents redox charges of RuHex bound to DNA with respect to the designated methylation level. Each data point represents the average of three repeat trails, and error bars represent the standard deviation of measurements $(\% \mathrm{RSD}=<5 \%$ for $n=3)$. 
Fig. 5.(A) Representative amplified PCR products of FAM134B promoter region in $1.5 \%$ agarose gel. FAM134B were present in all the samples (2-7) except non template control (8). Hundred basepairs DNA ladder is used for comparison. (B) Total redox charges for detecting FAM134B promoter region in three oesophageal cancer cell lines and unmethylated WGA and Jurkat DNA samples. (C) Typical CC curves fordetecting methylation of FAM134B promoter region in three oesophageal cancer cell lines, unmethylated WGA and Jurkat DNAand its corresponding background signal, and (D)Total redox charges for detecting FAM134B promoter region two normal (N1 and N2) and eight (P1-P8) oesophageal cancer tissue samples. Each data point represents the average of three repeat trails, and error bars represent the standard deviation of measurements $(\% \mathrm{RSD}=<5 \%$ for $n=3)$.Statistical significance was determined by pairwise comparison between 2 conditions using student $\mathrm{t}$ test. $*, p=0.005$ to 0.05 and $* *, p=0.0005$ to 0.005 . 
$\mu \mathrm{Ccm}^{-2}$

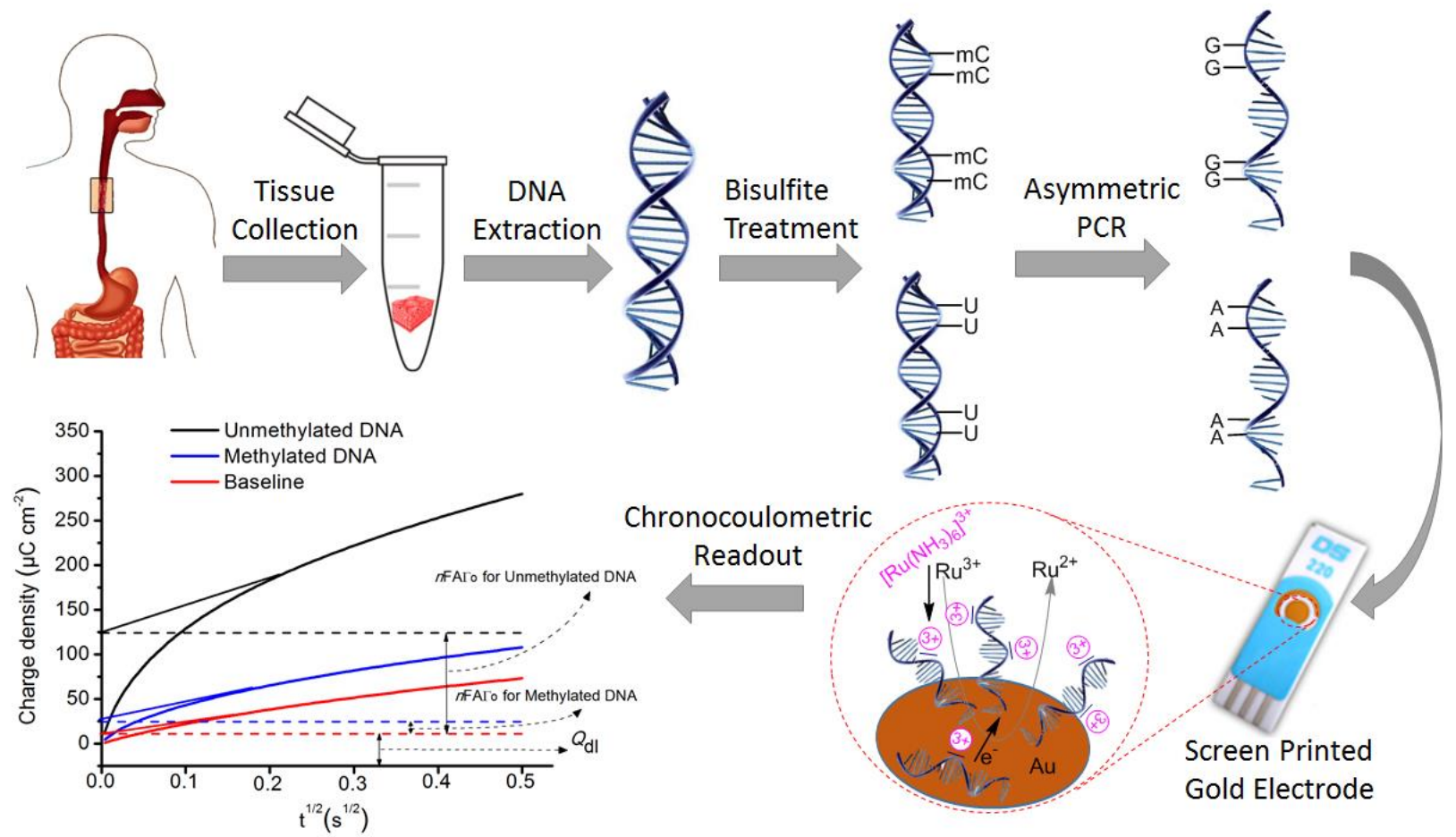

Fig. 1 


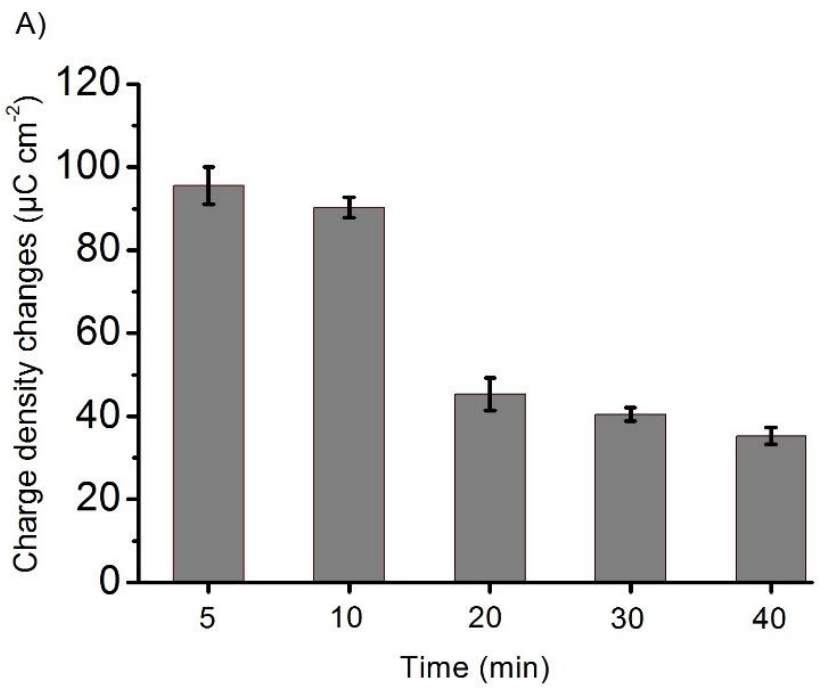

B)

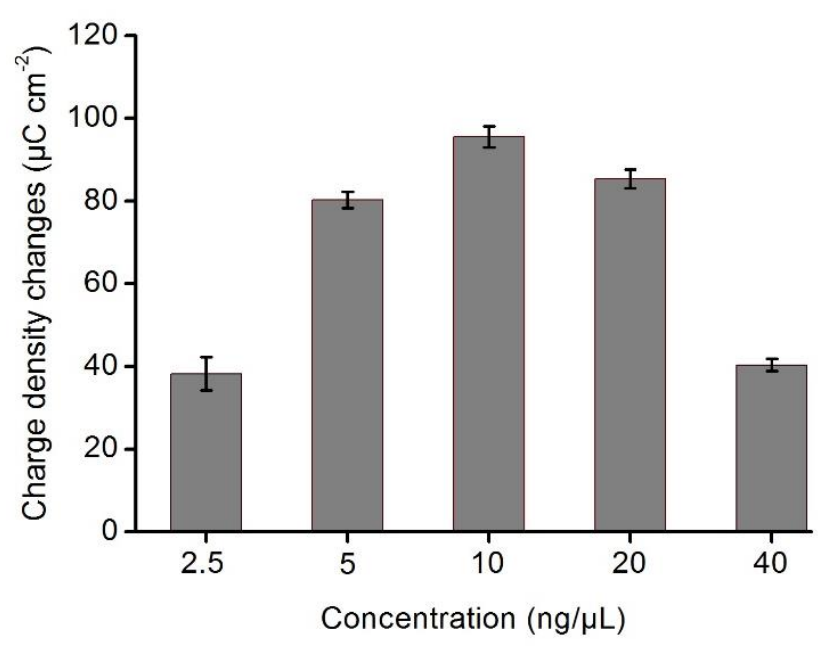

C)

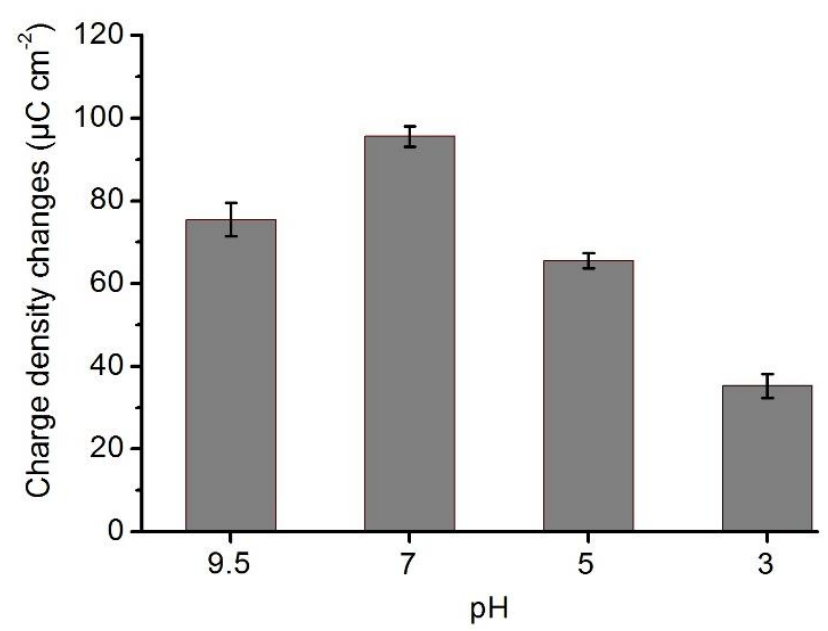

Fig. 2 
A)

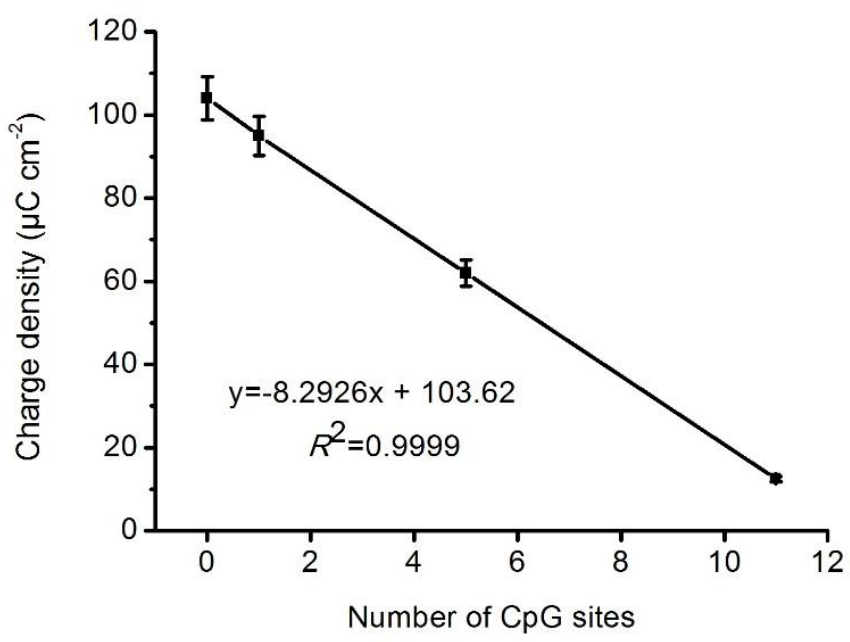

B)

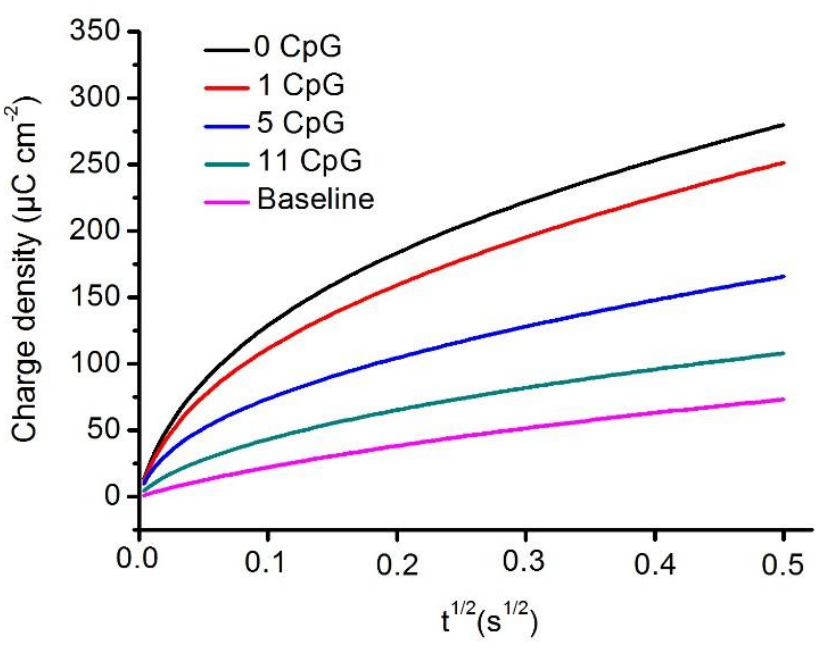

Fig. 3 
A)

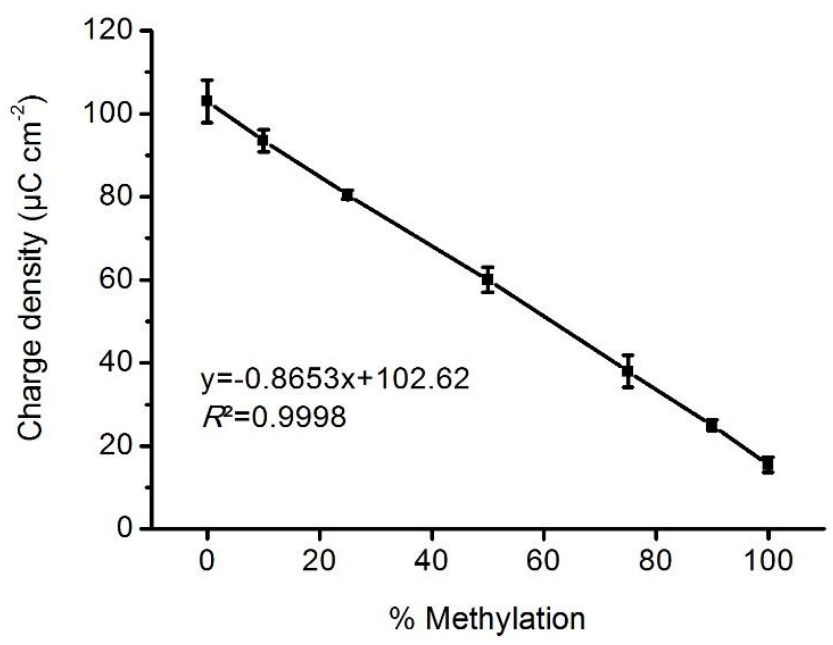

B)

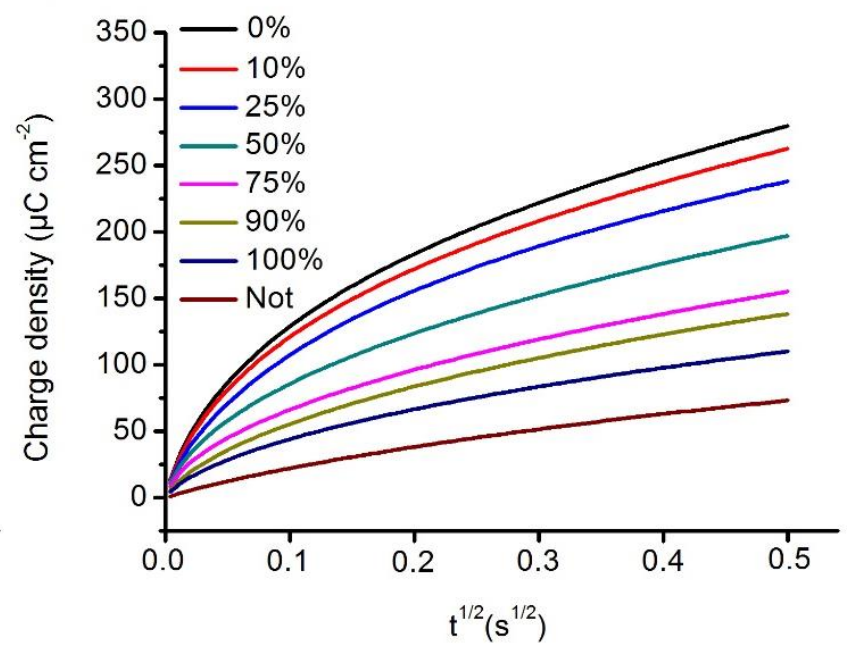

Fig. 4 
A)

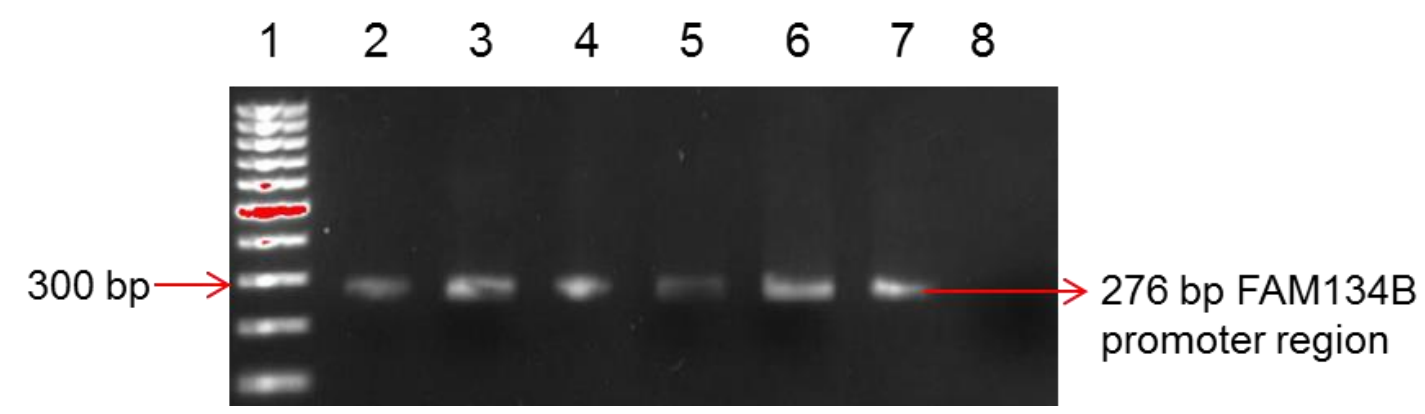

B)

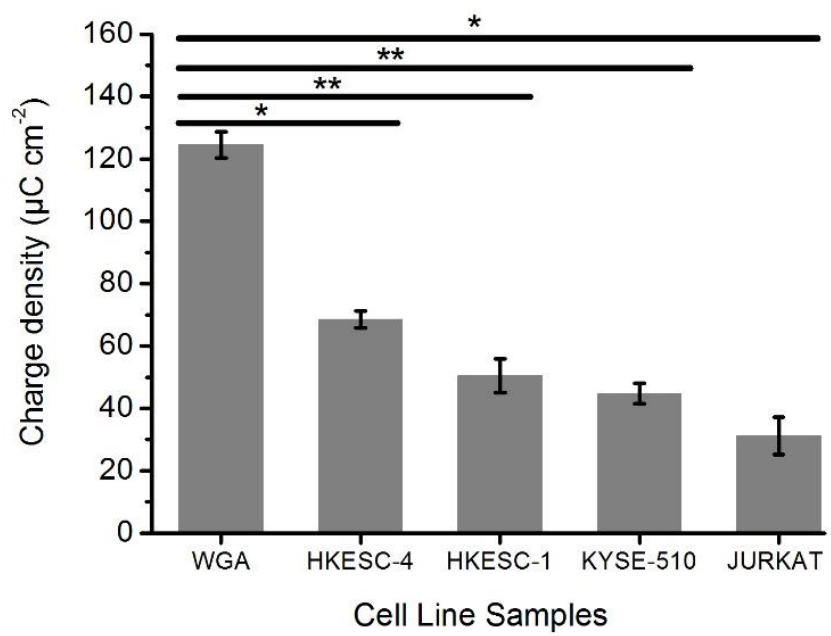

D)

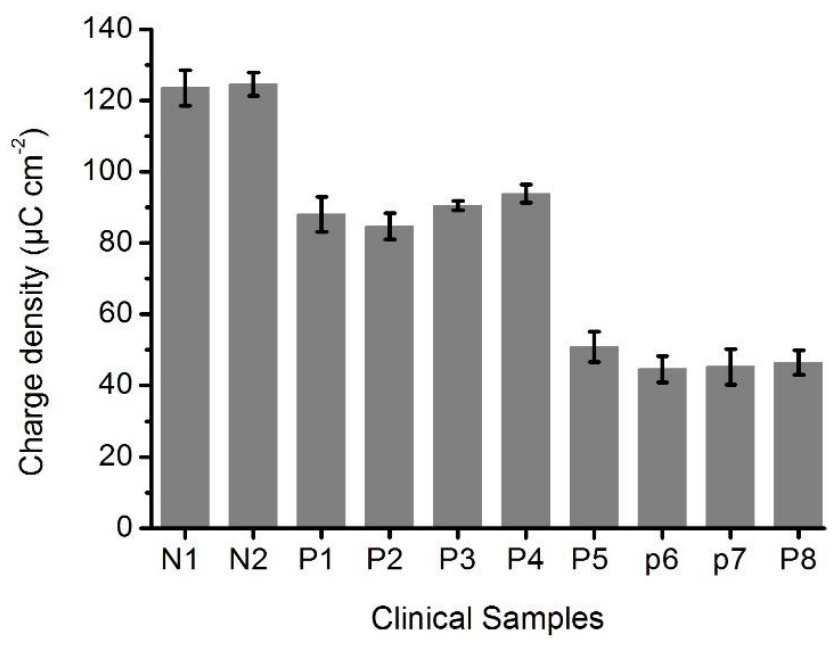

C)

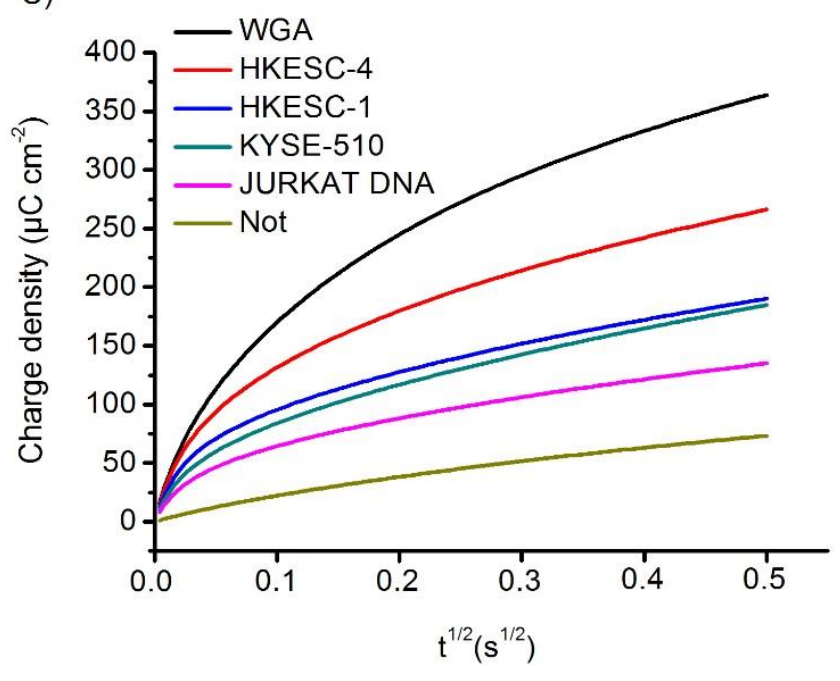

Fig. 5 